\title{
Influence of Admixtures on Mechanical Properties of Fibre Reinforced Concrete
}

\author{
Pulisai, G.B.Rameshkumar
}

\begin{abstract}
In this paper presents the mechanical properties of the fiber reinforced concrete. For that the experimental work should be done by using natural fiber that is coir ond it should be done on by using M5O grade of concrete. In this project we are going to use the admixtures also at different percentages by the replacement of the cement material. By adding the admixtures the characteristic strength of the concrete also improved when compared to the normal concrete. The mechanical properties like the compression strength, flexural strength, density and ductility of theconcrete be calculated in this experimental work the coir fiber was added up to the $0.4 \%$ of the binder volume of the concrete mixture. In this work the admixtures like flyash and silica fumealso mixed at $10 \%$ and $20 \%$ respectively. By using this experimental work, ductility, modulus of elasticity and ultra pulse value ofreinforced concrete also determined.
\end{abstract}

Key words-Modulus of elasticity,ultra pulse value, silica fume and flyash.

\section{INTRODUCTION}

High srength concretehas been very used to develop the mechanical properties of the concrete. It should be based on the choosing of the chemical admixtures for the concrete mixture and it should be widely used in the construction of the heavy industries. These chemical admixtures should be used to develop the mechanical properties of the concrete mixture like the compression strength of the concrete and it should be liesbetween 50 to $80 \mathrm{Mpa}$.

Nearly entirely these concretes takinginorganic additives contain for a change of motives of withassetimprovement , discount of penetrability ,higher crack resistance and strength factors .such as silica fume and fly ashhave a important talent in this situation.

The durability of the concrete mixture should been plays an important role in the field of the high strength concrete. Theultra pulse velocity is should used to be develop the durability of the concrete.

\section{LITERATURE REVIEW}

In this study, short distinct fibres specifically jute, fibre and bamboo has been examined for his or her quality for incorporation in cement concrete. The fleshly belongings of those fibers have shown no corrosionin a concrete medium. it's shown that viable and same mixes is obtained employing a special technique of proportioning. whereas compressive and tensile strengths of fiber concretes aren't any beyond those of management concrete ,their deformationcomportment shows improvement in malleabilityand shrinkage .Impact and fracture toughness of fiberconcretes are clearly higher.

\section{MATERIALS AND THEIR PROPERTIES}

\section{A. CEMENT}

Ordinary hydraulic cement (OPC) is far and away the foremost necessary sort of cement. The OPC was classified into 3 grade specifically 33 grade, 43 grade, fifty three grade relying upon the strength of the cement at twenty eight days once tested as perIS 8112- 1989. normal hydraulic cement of 53grade of cement is use during this experimental work. conformist weight of every cement bag was $50 \mathrm{~kg}$

\begin{tabular}{|c|c|c|c|}
\hline $\begin{array}{l}\text { Sr.n } \\
\text { o. }\end{array}$ & Characteristics & $\begin{array}{c}\text { Value obtained } \\
\text { experimentally }\end{array}$ & $\begin{array}{c}\text { Value } \\
\text { specified } \\
\text { by } \\
\text { IS:1226 } \\
9-1987\end{array}$ \\
\hline 1. & $\begin{array}{c}\text { Normal consistency } \\
(\%)\end{array}$ & 32 & 26 to 33 \\
\hline 2. & $\begin{array}{c}\text { Fineness of cement } \\
(\%)\end{array}$ & 8.32 & 10 \\
\hline 3. & $\begin{array}{c}\text { Setting time } \\
\text { (minutes) } \\
\text { 1initial2fi } \\
\text { nal }\end{array}$ & $\begin{array}{c}40 \text { Minutes } \\
360 \text { Minutes }\end{array}$ & $\begin{array}{c}30 \text { Minut } \\
\text { es } \\
600 \mathrm{Min} \\
\text { utes }\end{array}$ \\
\hline
\end{tabular}

\section{B. FINE AGGREGATES}

It ought to passing through IS Sieve four.75mm. Physical properties of aggregates verify per IS 2386-1968.It ought to have fineness modulus two.50- 3.50 and silt content shouldn't be over four-dimensional. Grading limit of Fine mixture confirming IS $383-1970$.

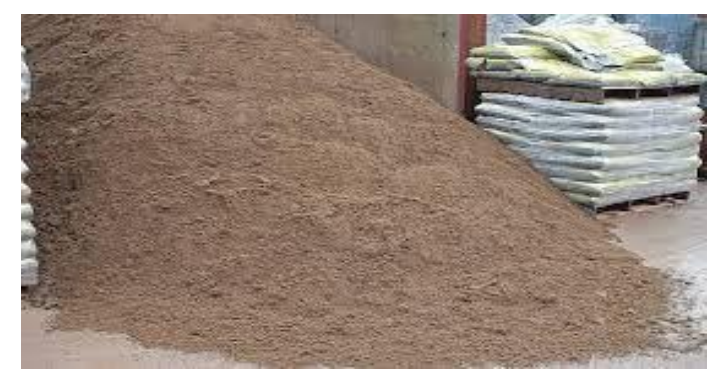

C.COURSE AGGREGATE

Revised Manuscript Received on April 12, 2019.

Pulisai, $2^{\text {nd }}$ yr. M.E, Structural engineering (Civil), Saveetha School of Engineering, Chennai, T.N, India. (E-mail: pulisaireddy1919@gmail.com)

Dr.G.B.Rameshkumar, M.E. Ph.D, Associate professor of structural engineering, Saveetha School of Engineering, Chennai, T.N, India. (Email: rameshkumargb@gmail.com) 
It must be hard, strong, solid, durable and spotless. It must be free from strain, believercovering, alkalis, vegetable matters and other harmfulmaterials. It should be conical shape. Crumbling pieces should be circumvented. The materials taken on respectively sieve was filled in gears and loaded separately.

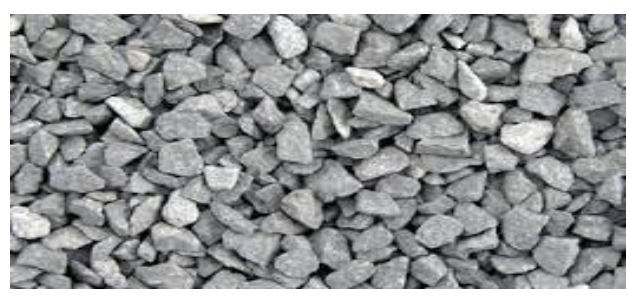

\section{WATER}

Locally obtainable portable water should standpermittedsince acids, oils, alkalis, tubers or other livinglayers.

\section{E. SUPER PLASTICIZER}

Generally so as to extend the workability the water content is to be accumulated provideda corresponding amount of cement is additionally more to stay the water cement magnitude relation constant, so the strength remains identical because the cement, being in fine state of division can have a abidance to flocculate in wet concrete. Gluonium fifty one is needed to enhance the workability.

\section{TEST SET UP:}

Moulds and equipment:

Cube : cube of the size $150 \mathrm{~mm} * 150 \mathrm{~mm} * 150 \mathrm{~mm}$ are used.

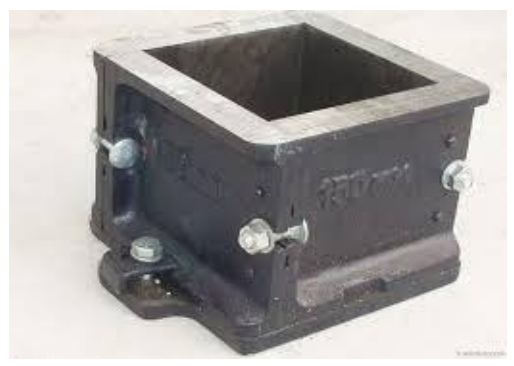

Cylinder: Cylinder mould of diameter $150 \mathrm{mmm}$ and height of $300 \mathrm{~mm}$ were utilized.

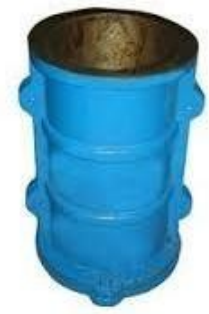

Casting: casting the concrete cubes and cylinders by using the concrete mixture of above mix design.

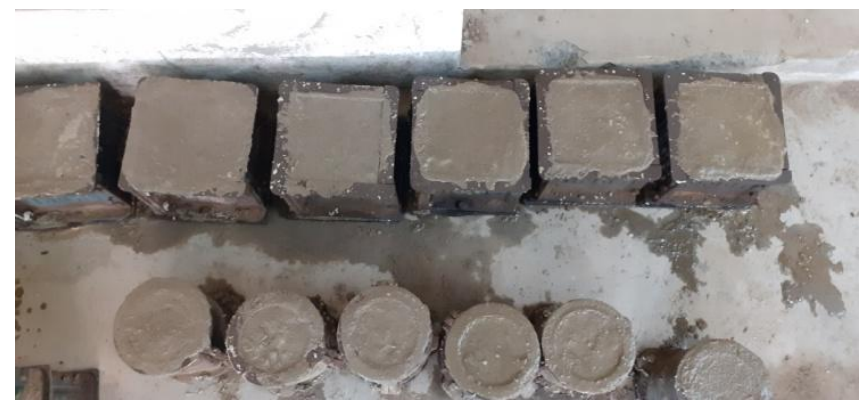

Curing: theabove casting moulds should be curing for the 7 days and 28 days .

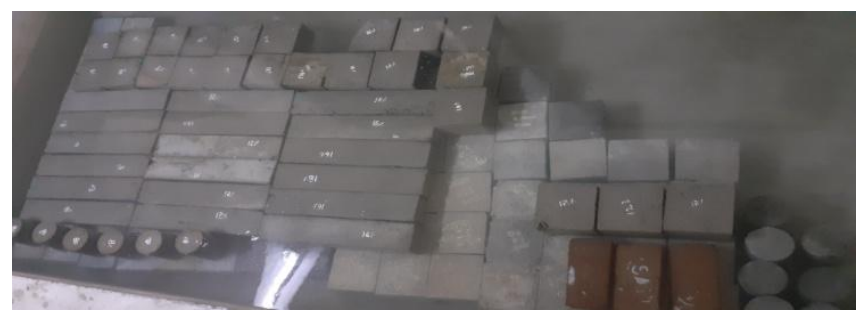

\begin{tabular}{|c|c|c|c|c|c|c|c|c|c|}
\hline \multicolumn{10}{|c|}{ Table 3. Test results and characteristics of hardened concrete } \\
\hline \multirow{2}{*}{ No } & \multirow{2}{*}{ Mix Reference } & \multicolumn{2}{|c|}{$\begin{array}{c}\text { Compressive } \\
\text { strength (Mpa) }\end{array}$} & \multicolumn{2}{|c|}{$\begin{array}{c}\text { Flexural } \\
\text { strength (Mpa) }\end{array}$} & \multicolumn{2}{|c|}{$\begin{array}{l}\text { Density } \\
\left(\mathrm{kN} / \mathrm{m}^{3}\right)\end{array}$} & \multirow{2}{*}{$\begin{array}{c}\text { 28-Day } \\
\text { dynamic } \\
\text { modulus of } \\
\text { elasticity } \\
\text { (Gpa) }\end{array}$} & \multirow{2}{*}{$\begin{array}{c}\text { 28-Day } \\
\text { ultrasonic } \\
\text { pulse velocity } \\
(\mathrm{km} / \mathrm{s})\end{array}$} \\
\hline & & 7 Day & $\begin{array}{c}28 \\
\text { Day }\end{array}$ & 7Day & 28 Day & 7 Day & 28 Day & & \\
\hline 1 & Control & 47.3 & 52.5 & 5.2 & 5.8 & 24.7 & 25.1 & 40.8 & . \\
\hline 2 & CFRC & 46.9 & 51.7 & 5.7 & 6.3 & 24.3 & 24.8 & 42.6 & 43.8 \\
\hline 3 & CFR DSFC & 44.1 & 50.5 & 5.5 & 6.2 & 23.4 & 24.1 & 41.1 & 42.9 \\
\hline 4 & CFRFAC & 48.3 & 56.6 & 5.3 & 7.1 & 23.9 & 24.3 & 44.4 & 44.2 \\
\hline
\end{tabular}

\section{TESTS AND RESULTS}

\section{COMPRESSION STRENGTH:}

The cube speciemens were testedon compression testing machine of capacity $2000 \mathrm{KN}$.

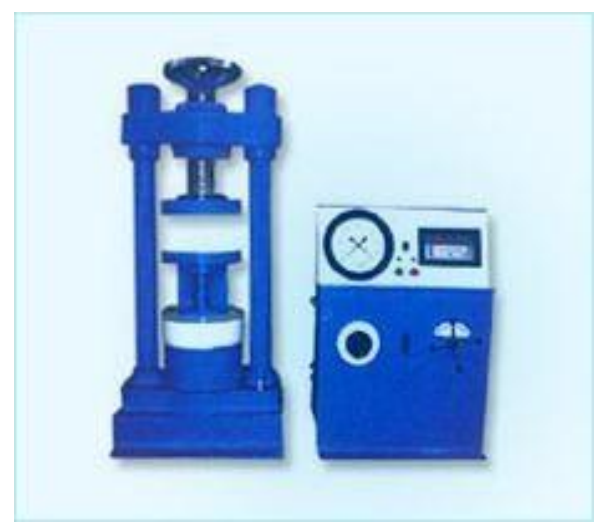

COMPRESSIVESTRENGTH $=($ ULTIMATELOAD $) \quad /(A R E A$ OF CROSS SECTION). 


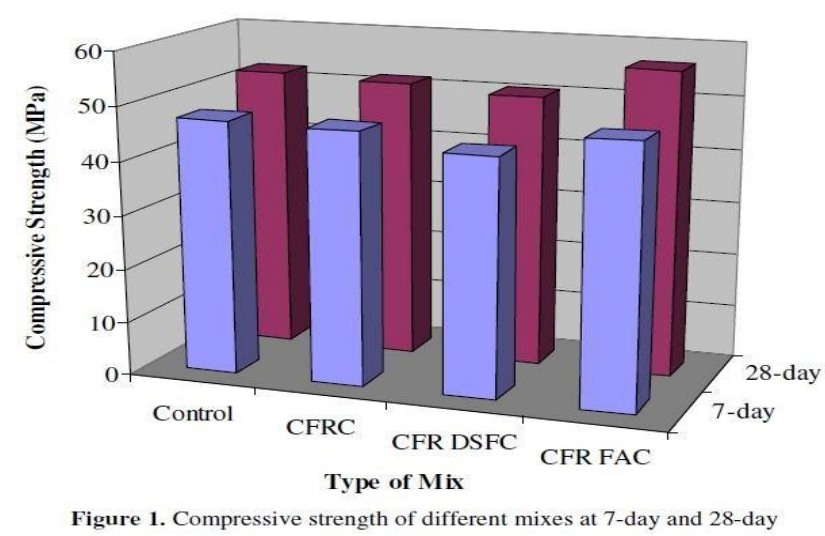

a. Coir fibre reinforced concrete (CFRC)

Compressive strenth ofCFRC was one.5\% lower compared thereto of management concrete at that age aof twenty eight days ,coir fibres reduced comnpressive strength of concreteby increasing voidscontent thanks to lower potency in real compaction. Reality of the Arctic teams in fibre began wasteful bonding between fibre andthe hydrophobic background, since adry fibre fibre interests a large quantity of wetness glad and condensed wettability in concrete mixture.

b. Coir fibre reiforcedfly ash concrete(CFR FAC)

c. Coir Fibre Reinforced densified silicica fume concrete(CFRDSFC)

Flexural tensile strength.

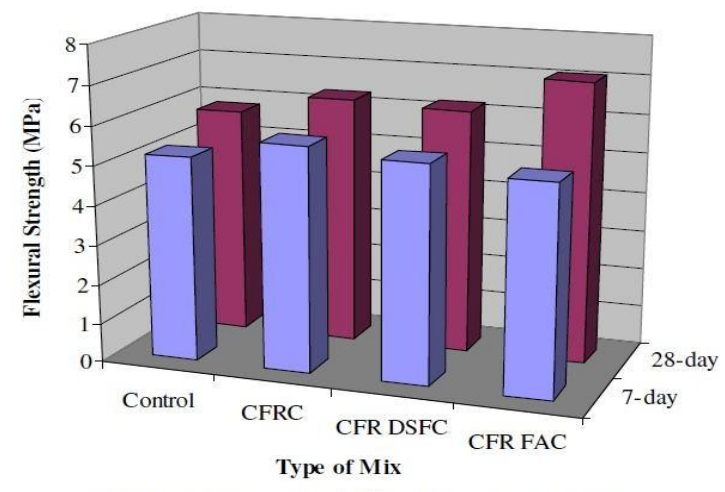

Figure 2. Flexural strength of different mixes at 7-day and 28-day

\section{Modulus of elasticity}

The modulus of physical property of various mixes at the age of twenty eight days. examination to thePHSC, the dynamic physical property of modulusof CFRC,CFRDSFC and CFRFAC improved by concerning four-dimensional, $1 \%$ and Sep 11 severally. Among the factors poignant modulus of physical property of concrete, wetness content plays a vital role.

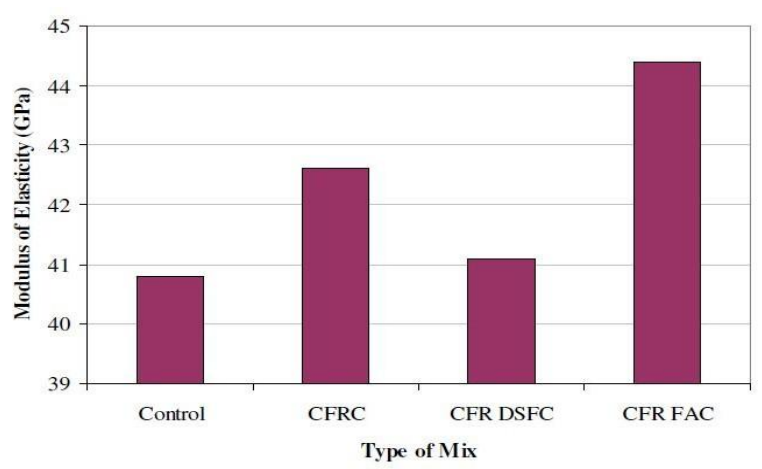

Figure 3. Flexural strength of different mixes at 7 -day and 28-day

\section{DENSITY}

Densities of 4 admixtures ar within the vary of 2400-2600 $\mathrm{kg} / \mathrm{m}^{3}$ that ar thought of on top of the vary for standard concrete.

\section{DUCTILITY}

The ductility of the material is as shown below the figure:
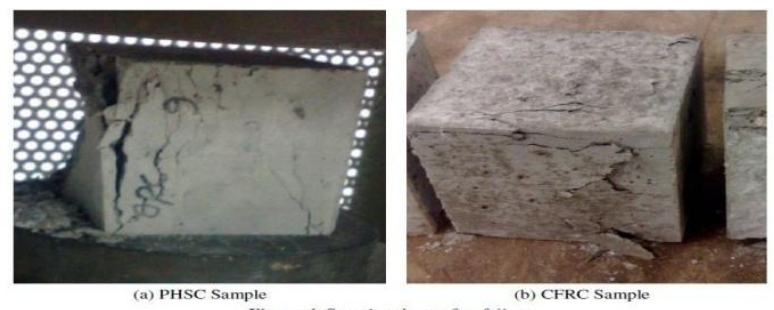

\section{CONCLUSSION}

When fibre reinforcedconcrete is plays an important role in construction field . so this project produce the mechanical properties of the fibre reinforced concrete of using the different admixtures by producing the high strength when compared to the normal concrete .it gives different values for the adding of the different admixtures for the 7 days and 28 days .

\section{REFERENCES}

1. VanchaiSata,ChaiJaturapitakkul,KraiwoodKiattikomol., Vol. 21, (2007),1589-1598.

2. KraiwoodKiattikomol,VanchaiSata,

TheerarachLeekeeratikul., Vol. 34, (2004),549-555.

3. RafatSiddique., Vol. 34, (2004), 487 - 493.

4. Sun-KyoungGwang., Vol.15 No.5(2003), 747-758 